\title{
Interim Canadian recommendations for the use of a fractional dose of yellow fever vaccine during a vaccine shortage
}

\author{
Yellow Fever Working Group ${ }^{1}$ on behalf of the Committee to Advise on Tropical Medicine and \\ Travel (CATMAT)
}

\section{Summary}

This statement outlines interim recommendations intended for use during yellow fever vaccine shortages only. The recommendations differ from the standard recommendations for yellow fever vaccination in the Canadian Immunization Guide and in the Committee to Advise on Tropical Medicine and Travel (CATMAT) Statement for Travellers and Yellow Fever.
Affiliation

${ }^{1}$ Note: Members of the Yellow Fever Working Group are listed in the Acknowledgements section

Correspondence: catmat. secretariat@phac-aspc.gc.ca

Suggested citation: Yellow Fever Working Group on behalf of the Committee to Advise on Tropical Medicine and Travel (CATMAT). Interim Canadian recommendations for the use of a fractional dose of yellow fever vaccine during a vaccine shortage. Can Comm Dis Rep 2016;42:158-60. https://doi.org/10.14745/ccdr.v42i08a02

\section{Introduction}

Yellow fever vaccine shortages pose a challenge. Travel clinics may be allotted a small fraction of the number of vaccines typically ordered, or in some cases, travel clinics will not have access to the yellow fever vaccine until a new supply of the vaccine is available. There is currently only one licensed marketer of the vaccine in Canada.

In 2016, there have been calls for the use of a fractional dose of yellow fever vaccine to address a global yellow fever vaccine shortage, a measure which would allow for immunization of a greater number of people during the vaccine shortage (1-3). This suggestion is primarily based on three studies which have shown that doses in the range of $1 / 10$ to $1 / 5$ of the usual $0.5 \mathrm{ml}$ subcutaneous dose are protective based on laboratory criteria.

On 17 June 2016, the World Health Organization (WHO) released a statement that the WHO Strategic Advisory Group of Experts (SAGE) on Immunization found that the use of a fifth of a standard vaccine dose $(0.1 \mathrm{ml}$ instead of $0.5 \mathrm{ml})$ would provide protection against yellow fever for at least 12 months based on a review of existing evidence (4). The WHO states that the fractional dose of yellow fever vaccine can be considered a safe and effective approach to control an urban outbreak in case of vaccine shortages.

CATMAT formed a working group to review the evidence and make interim recommendations on the use and documentation of fractional doses of yellow fever vaccine in Canada intended for use during yellow fever vaccine shortages only. Each member was a volunteer, and none declared a relevant conflict of interest. The recommendations differ from the standard recommendations for yellow fever vaccination in the Canadian Immunization Guide (5) and in the Committee to Advise on
Tropical Medicine and Travel (CATMAT) Statement for Travellers and Yellow Fever (6).

\section{Methods}

A literature search for evidence related to the immunogenicity of a fractional dose of yellow fever vaccine was conducted. Evidence was retrieved by performing searches in electronic databases (Ovid MEDLINE, Embase, Global Health and Scopus). The search spanned the initial date for each database until June 2016 and 49 results were identified. Titles and abstracts of these results were reviewed and selected for inclusion based on relevancy to the research question.

\section{Results}

In 2008, Roukens et al studied the effect of a one-fifth dose of yellow fever vaccine administered intradermally. All subjects developed titres of neutralizing antibody considered to be protective (7). The average subject age was 27 years with a wide adult age range (18 to 70 years).

In 2013, Martins et al studied seroconversion and viremia responses to the use of full dose and five different dilutions of the usual human dose of 17-DD yellow fever vaccine administered subcutaneously (8). There was little difference in immune response down to a dilution of 1:50.

In a 2014 extension of the Martins study (using the same patient data and collected blood), Campi-Azevedo studied serum biomarkers of cellular immunity responses using fractional doses (9). There was evidence of protection at dilutions down to 1:50. However, consistent findings of equivalency to a full dose 
across all markers of immunity (serology, viremia and cellular immunity) were found down to a 1:10 dilution. In the Martins and Campi-Azevedo investigations, all subjects were healthy young males with an average age of 19 years.

Although the results of these studies are encouraging, this constitutes a limited evidence base. Further research is needed to determine the effectiveness of fractional doses, especially in young children.

\section{Recommendations}

Under normal circumstances, a recommendation for use of fractional dose of yellow fever vaccine would not be made for travellers. However, some travellers going to yellow fever endemic or epidemic regions may not have access to a full dose of yellow fever vaccine, and as such, these travellers face the choice of not receiving a vaccine or receiving a fractional dose of vaccine.

In view of this situation, CATMAT makes the following recommendations, applicable to individuals for whom the standard yellow fever vaccine recommendations apply, including young children:

- For travel to a region of a country with risk of yellow fever, health care professionals should first emphasize the importance of receiving a full dose of vaccine or otherwise postponing the trip. This is especially critical for travel to areas experiencing an ongoing outbreak of the disease.

- If a traveller must travel to an endemic area, especially to areas experiencing an ongoing outbreak of yellow fever, and a full dose cannot be located after reasonable efforts, a fractional dose may be administered. The dose should be $1 / 5$ of the usual dose $(0.1 \mathrm{ml}$ instead of $0.5 \mathrm{ml}$ ) administered by the traditional subcutaneous route. As with a full dose, a fractional dose is considered protective 10 days after it is administered to a person who has never before received the yellow fever vaccine.

- If a traveller planning a high risk itinerary receives a fractional dose of yellow fever vaccine, and then later finds that a full dose has become available, this dose may be administered and the International Certificate of Vaccination or Prophylaxis (ICVP) may be issued.

- Once reconstituted, the vaccine vial should be stored between $2^{\circ}$ and $8^{\circ}$ Celsius, and used within one hour. Thus, it will be necessary to vaccinate several people within that hour in order to efficiently use the contents of the vial in the allotted time. The health care professional may find that the use of disposable $1 \mathrm{cc}$ insulin syringes with non-detachable needle wastes less vaccine. Four, possibly five, doses may be obtained from one vial. Strict aseptic technique should be observed.

- If fewer than five doses are being administered, it is recommended that the entire contents of the vial be used, equally distributed among those being immunized. This will allow for the administration of somewhat more than $0.1 \mathrm{ml}$ per person.
- $\quad$ Based on available data, a fractional dose (1/5) should be considered protective for one year. Protection may be longer, however long term data is lacking. No recommendation is made at this time regarding repeat fractional dose immunization for subsequent travel.

- $\quad$ Once the supply of yellow fever vaccine is restored in Canada, the use of fractional doses should be discontinued.

- $\quad$ Practitioners are reminded that the WHO now considers a single full dose of yellow fever vaccine protective for life regardless of when it is administered.

\section{Documentation of fractional dose yellow fever vaccination}

The WHO states that a fractional dose of the yellow fever vaccine would not qualify for a yellow fever certificate under the International Health Regulations (IHR) (4). Therefore CATMAT does not recommend that practitioners use the official International Certificate of Vaccination or Prophylaxis (ICVP) card to document a fractional dose.

One option for documentation is the use of the Certificate of Medical Contraindication to Vaccination provided by the Public Health Agency of Canada. An explanation can be written inside informing that a fractional dose of $0.1 \mathrm{ml}$ of the yellow fever vaccine was administered subcutaneously due to a severe vaccine shortage.

\section{Additional resources and useful links}

Government of Canada - Yellow Fever Vaccinations Centres in Canada. http://www.phac-aspc.gc.ca/tmp-pmv/yf-fj/index-eng. php

World Health Organization - Vaccination requirements and recommendations for international travellers. http://www.who. int/ith/en/

\section{Acknowledgements}

This statement was developed by the Yellow Fever Working Group: Teitelbaum P (Chair), Bui Y, Libman M, Pernica J and Abdel-Motagally M.

CATMAT members: McCarthy A (Chair), Acharya A, Boggild A, Brophy J, Bui Y, Crockett M, Greenaway C, Libman M, Teitelbaum $P$ and Vaughan $S$.

Liaison members: Audcent T (Canadian Paediatric Society), Gershman M (United States Centers for Disease Control and Prevention) and Pernica J (Association of Medical Microbiology and Infectious Disease Canada).

Ex officio members: Marion D (Canadian Forces Health Services Centre, Department of National Defence), Rossi C (Directorate of Force Health Services Group, Department of National Defence), McDonald P (Division of Anti-Infective Drugs, Health Canada) 
and Schofield S (Pest Management Entomology, Department of National Defence).

\section{Conflict of interest}

None.

\section{References}

1. Monath TP, Vasconcelos PF. Yellow fever. J Clin Virol 2015 Mar;64:160-173.

2. Monath TP, Woodall JP, Gubler DJ, Yuill TM, Mackenzie JS, Martins RM, et al. Yellow fever vaccine supply: a possible solution. Lancet 2016 Apr 16;387(10028):1599-1600.

3. Lucey D, Gostin LO. A Yellow Fever Epidemic: A New Global Health Emergency? JAMA 2016 May 9.

4. World Health Organization. Lower doses of yellow fever vaccine could be used in emergencies. 2016 http://www. who.int/mediacentre/news/statements/2016/yellow-fevervaccine/en/.
5. Public Health Agency of Canada. Canadian Immunization Guide. Part 4: Active Vaccines, Yellow Fever Vaccine. 2012 http://www.phac-aspc.gc.ca/publicat/cig-gci/p04-yfev-fiejeng.php.

6. Committee to Advise on Tropical Medicine and Travel. Statement for Travellers and Yellow Fever. Can Comm Dis Rep 2013;39(ACS-2). http://www.phac-aspc.gc.ca/publicat/ ccdr-rmtc/13vol39/acs-dcc-2/index-eng.php.

7. Roukens $A H$, Vossen AC, Bredenbeek PJ, van Dissel JT, Visser LG. Intradermally administered yellow fever vaccine at reduced dose induces a protective immune response: a randomized controlled non-inferiority trial. PLOS ONE 2008;3(4):e1993.

8. Martins RM, Maia MdLS, Farias RHG, Camacho LAB, Freire MS, Galler R, et al. 17DD yellow fever vaccine: a double blind, randomized clinical trial of immunogenicity and safety on a dose-response study. Hum Vaccin Immunother 2013 Apr;9(4):879-888.

9. Campi-Azevedo AC, de Almeida Estevam P, CoelhoDos-Reis JG, Peruhype-Magalhaes V, Villela-Rezende G, Quaresma PF, et al. Subdoses of 17DD yellow fever vaccine elicit equivalent virological/immunological kinetics timeline. BMC Infect Dis 2014;14:391.

\title{
All you want to know about Zika Virus Canada Communicable Disease Report
}

May 5, $2016 \bullet$ Volume 42-5

\author{
Read the updated Canadian \\ recommendations on the \\ prevention and treatment \\ of Zika virus
}

\section{Read it now: phac-aspc.gc.ca/publicat/ccdr-rmtc/

Canadă"
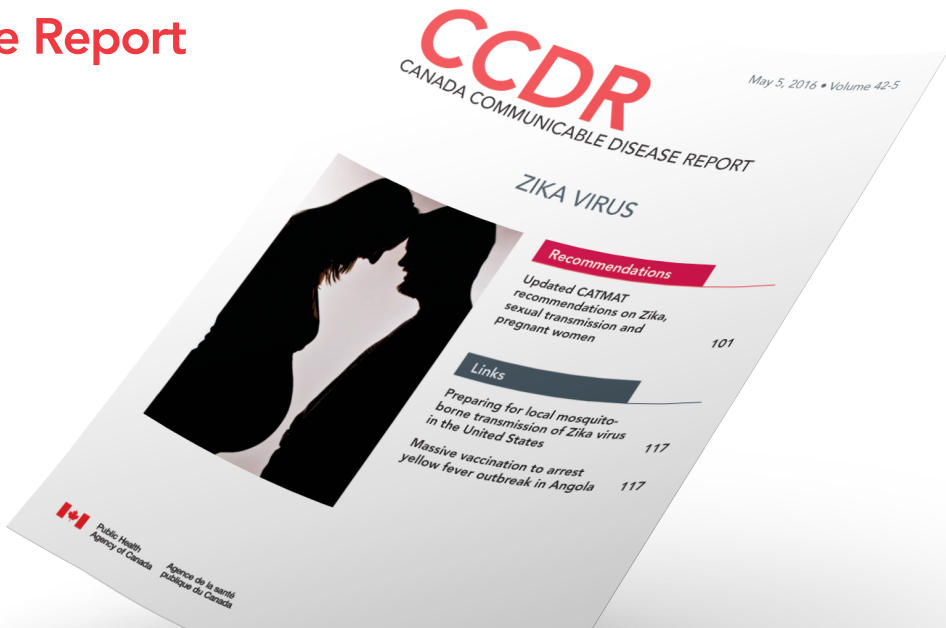